\title{
PERANCANGAN VIDEO ANIMASI INFOGRAFIS “CARA URBAN GARDENING YANG TEPAT UNTUK WILAYAH KOTA DKI JAKARTA"
}

\author{
Nadya $^{1}$, Yana Erlyana ${ }^{2}$ \\ 1,2Desain Komunikasi Visual, Fakultas Teknologi dan Desain, Universitas Bunda Mulia \\ Jalan Lodan Raya No2, Jakarta Utara \\ 1nadya@bundamulia.ac.id, 2yerlyana@bundamulia.ac.id
}

\begin{abstract}
Abstrak: Jakarta memiliki tingkat polusi udara terburuk ketiga di dunia. Dalam hal ini, pemerintah mengeluarkan kebijakan dalam menetapkan peraturan lahan hijau sebagai solusi mengatasi polusi udara, yang disebut dengan Ruang Terbuka Hijau (RTH). Namun ruang terbuka hijau di Jakarta saat ini baru mencapai 14,9 persen, padahal target yang diinginkan sebesar 30 persen. Untuk itu perlu juga upaya dari masyarakat setempat untuk membantu meningkatkan target pencapaian 10 persen RTH privat yaitu dengan melakukan kegiatan menanam di area terbatas yang dikenal dengan sebutan urban gardening. Berdasarkan pernyataan tersebut, diperlukan langkah awal yang baik dalam memberikan penyuluhan kepada masyarakat mengenai kegiatan urban gardening ini. Hal ini karena pengetahuan masyarakat perkotaan khususnya di Jakarta masih minim mengenai konsep tanam-menanam dan penataan taman, terutama di lahan tempat tinggal yang sempit dan padat. Dalam penelitian ini membahas mengenai perancangan media informasi tentang urban gardening dengan menggunakan teknik animasi infografis. Tujuan yang ingin dicapai dari penelitian ini adalah merancang video infografis tentang urban gardening yang sesuai target pasar. Penelitian ini menggunakan desain penelitian tindakan peran serta (penelitian terapan) atau disebut participatory action research (PAR) dengan partisipasi kontraktual. Hasil dari pernelitian ini berupa karya rancangan video animasi infografis mengenai cara urban gardening yang tepat unutk wilayah kota DKI Jakarta.
\end{abstract}

Kata kunci : penanaman, kota, animasi, infografis

Abstract: Jakarta has the third worst level of air pollution in the world. In this case, the government issued a policy in establishing green land regulations as a solution to overcome air pollution, called the Green Open Space (RTH). But the green open space in Jakarta currently only reaches 14.9 percent, whereas the desired target is 30 percent. For this reason, efforts from the local community are also needed to help to increase the target of achieving 10 percent of private green open space by planting in limited areas or called urban gardening. Based on this statement, a good initial step is needed in providing counseling to the public regarding this urban gardening activity. This is because the knowledge of urban communities, especially in Jakarta is still minimal about the concept of planting and structuring parks, especially on land that is narrow and dense. This study 
discussed the design of information media about urban gardening using infographic animation techniques. This study used a participatory action research design (applied research) or called participatory action research (PAR) with contractual participation. The aim of this research is to design an infographic video about urban gardening that fits the target market.

Keywords: urban gardening, animation, infographic Profil singkat penulis:

Nadya, S.Ds., MM., menyelesaikan Pendidikan Sarjana Desain dan Magister Manajemen di Universitas Bunda Mulia, Jakarta Utara. Awalnya bekerja di bidang desain grafis pada tahun 2008 hingga tahun 2010 memutuskan untuk mengajar sebagai dosen di Universitas Bunda Mulia. Selama berkecimpung di dunia Pendidikan, Penulis turut aktif dalam melakukan penelitian dan menerbitkan karya ilmiah. Penulis juga pernah membuat komik berseri berjudul "Petualangan bersama Leli dan Leo" yang didedikasikan kepada Dinas Kelautan dan Pertanian Provinsi DKI Jakarta. Penulis sekarang aktif juga dalam membina klub animasi dan mengerjakan proyek sosial Bersama Yayasan Children of Nation dalam membuat film serial animasi 2 dimensi berjudul "Lulu and Friends".

Yana Erlyana, S.Sn., MM., seorang praktisi dalam dunia desain grafis serta aktif sebagai pengajar di Univeristas Bunda Mulia, untuk mata kuliah desain kemasan, brand identity dan book design. Selama menjadi pengajar, penulis aktif dalam penelitian dan penerbitan karya ilmiah. Penulis juga pernah menjadi partisipan dalam pameran nasional, Jakarta Fashion Week dan beberapa penghargaan lomba tingkat nasional salah satunya Gold Winner dalam ISPRIMA 2020 dengan membawa newsletter Garisbawah yang dibina penulis.

\section{PENDAHULUAN}

DKI Jakarta merupakan ibukota Negara Indonesia yang cukup padat penduduk dengan segala aktivitasnya. Meskipun begitu, ternyata kepadatan penduduk menuai berbagai permasalahan, seperti kemacetan, banjir, hingga polusi udara. Jakarta memiliki tingkat polusi udara terburuk ketiga di dunia yaitu tercatat di angka 157 kategori tidak sehat (Rimadi, 2019). Dalam hal ini, pemerintah mengeluarkan kebijakan dalam menetapkan peraturan lahan hijau sebagai solusi mengatasi polusi udara, yang disebut dengan Ruang Terbuka Hijau (RTH). Namun ruang terbuka hijau di Jakarta saat ini baru mencapai 14,9 persen (Subagio, 2019), padahal target Pemprov DKI Jakarta terhadap RTH yaitu sebesar 30 persen sesuai Peraturan Menteri Pekerjaan Umum No: 05/PRT/M/2008, yaitu 20 persen RTH Publik, dan 10 persen RTH Privat. 
Walaupun pemerintah sudah berupaya membangun RTH di Jakarta, pada kenyataannya masih belum menyentuh target. Untuk itu perlu juga upaya dari masyarakat setempat untuk membantu meningkatkan target pencapaian 10 persen RTH privat, bahkan jika perlu melebihi target. Upaya tersebut antara lain dengan memanfaatkan ruang terbuka pribadi sebagai lahan hijau yang sesuai ketentuan penanaman hijau atau dikenal dengan istilah urban gardening. Istilah urban gardening adalah bagaimana mengolah tanaman menjadi taman hijau dengan kondisi lokasi penanaman di perkotaan yang minim medium tanam. Menurut Indah Susilowati, (2013) konsep pengembangan RTH pada permukiman kepadatan tinggi dalam konsep human settlement diarahkan pada pengembangan fungsi RTH dalam pencapaian elemen nature (alam) dan elemen society (masyarakat). Pada elemen society, masyarakat dapat mengembangkan RTH pada pekarangan rumah tinggal.

Berdasarkan pernyataan tersebut, diperlukan langkah awal yang baik dalam memberikan penyuluhan kepada masyarakat mengenai kegiatan urban gardening ini. Hal ini karena pengetahuan masyarakat perkotaan khususnya di Jakarta masih minim mengenai konsep tanam-menanam dan penataan taman, terutama di lahan tempat tinggal yang sempit dan padat. Beberapa langkah penyuluhan yang dapat ditempuh adalah memberikan informasi seputar urban gardening, baik dari pengetahuan, jenis, fungsi, hingga cara menanam yang tepat dan persiapannya. Cara memberikan informasi penyuluhan tersebut dapat bervariasi tergantung target pasar, materi yang disampaikan, dan seberapa besar jangkauan yang diinginkan. Salah satu cara penyampaian informasi yang sesuai adalah dengan memanfaatkan media yang sinergi dengan perkembangan teknologi sekarang yaitu dengan menggunakan media audio visual berbentuk video animasi infografis (Reno, Siahaan and Alfian, 2018; Sari, 2019). Pemilihan media ini juga menimbang infografis sebagai cara untuk memberikan informasi kepada masyarakat dalam bentuk steno visual yang mudah dimengerti. Hal ini 
didukung dengan penelitian Yuvaraj (2017) yang menyatakan bahwa masyarakat selalu menggunakan infografis, sebagai bentuk steno visual, untuk mengkomunikasikan informasi dengan cara yang dapat dimengerti dalam sebuah paragraf atau halaman jika dijelaskan dengan kata-kata (Yuvaraj, 2017).

Infografis apabila dipadukan dengan animasi dapat digunakan sebagai alat yang efektif untuk komunikasi dalam pedagogi dan, jika digunakan dengan benar, dapat meningkatkan kinerja akademik siswa dalam Pendidikan ( $\mathrm{M}$ and Tyagi, 2018). Setiap media animasi memiliki keunikannya sendiri dalam hal fitur fisik dalam desain karakter (Stevina and Purwaningsih, 2018; Alfatra, Suminto and Purwacandra, 2019; Priyono et al., 2020). Dalam hal ini, video animasi dapat digunakan sebagai bentuk penyampaian informasi yang menarik dan lebih jelas karena didukung proses detail ilustrasi yang bergerak dalam menyampaikan informasi berupa penyuluhan, pendidikan, hingga pembelajaran (Handani, Utami and Kusmira, 2017). Produksi animasi bersifat taktil, multimodal, dan multisensor yang memungkinkan aplikasi luas bersama dengan alat pembelajaran tradisional, menargetkan berbagai jalur pembelajaran dengan pendekatan visual, auditori, dan kinestetiknya (Rutherford, 2019). Para peneliti menemukan bahwa para siswa menyatakan antusiasme yang besar terhadap animasi sebagai media pengajaran online (Dewi and Rino, 2018; Poggiali, 2018). Dalam penelitian Dur (2014) mengatakan bahwa pikiran manusia dapat mentransfer informasi visual dengan sangat cepat dan dengan cara yang lebih efisien serta permanen dibandingkan dengan mentransfer informasi secara tertulis atau verbal. Fitur paling penting dari infografis adalah mengubah massa informasi yang kompleks dan tidak sistematis menjadi struktur yang dapat dipahami dengan membuat cerita darinya dan perkembangan paling penting dalam beberapa tahun terakhir untuk infografis adalah mendapatkan fitur definisi tinggi dan fitur interaktivitas sebagai hasil dari kemajuan teknologi. Dari berbagai riset penelitian terdahulu tersebut, maka dapat 
disimpulkan bahwa penggunaan media informasi berupa video animasi infografis merupakan media yang tepat dan sesuai target audiens.

\section{METODE PENELITIAN}

Pada penelitian ini mengunakan desain penelitian tindakan peran serta (penelitian terapan) atau disebut participatory action research (PAR) dengan partisipasi kontraktual, yaitu menyiapkan partisipan yang dikontrak ke dalam proyek peneliti sebagai bagian dalam penelitian dan eksperimen (Guntur, 2016). Partisipan yang di kontrak dalam penelitian ini 4 orang mahasiswa peminatan multimedia animasi yang dibagi menjadi beberapa kelompok kerja. Tahapan kerja dimulai dari pra-produksi yaitu: Ide \& konsep; Storyline/Skenario; Pembentukan karakter \& Aset; Storyboard; Dubbing awal (jika berdialog); Musik dan sound FX; Animatic. Kemudian tahapan produksi yaitu: Aset; Layout; Key motion; In Between; Animation; Background. Tahapan terakhir post-produksi yaitu: Composite; Editing; Rendering; Pemindahan film kedalam berbagai media; Publikasi.

Untuk pengembangan materi informasi penyuluhan penanaman urban gardening, digunakan model dan desain pembelajaran Dick and Carey karena sesuai dengan teori yang dikemukakan bahwa dalam pembelajaran tersebut termasuk dalam lingkungan pendidikan non formal mandiri, yaitu pembelajaran yang meliputi warga belajar, tutor atau guru, materi, dan lingkungan yang dapat digunakan untuk belajar secara mandiri (Riyanti, 2018). Sehingga pada pengembangan materi penelitian ini mengunakan 20 anak-anak RPTRA Dharma Suci dengan range usia 8-12 tahun bersamaan dengan orang tuanya sebagai sampling, hal ini disebabkan karena lokasi yang menjadi target awal penyebaran. Serta diskusi forum bersama guru-guru SD Bunda Mulia School sebagai bahan pertimbangan materi dasar. 


\section{HASIL DAN DISKUSI}

Urban gardening merupakan sebuah kegiatan menanam dan menumbuhkan tanaman di area padat penduduk atau lahan kecil yang ditujukan untuk konsumsi pribadi maupun untuk dekorasi. Dalam Jurnal Agroteknologi (Fauzi, Ichniarsyah and Agustin, 2016), Pertanian kota merupakan kegiatan pertumbuhan, pengolahan, dan distribusi pangan serta produk lainnya melalui budidaya tanaman dan peternakan yang intensif di perkotaan dan daerah sekitarnya, dan menggunakan (kembali) sumber daya alam dan limbah perkotaan, untuk memperoleh keragaman hasil panen dan hewan ternak. Bentuknya meliputi pertanian dan peternakan kecil-intensif, produksi pangan di perumahan, land sharing, taman-taman atap (rooftop gardens), rumah kaca di sekolah-sekolah, restoran yang terintegrasi dengan kebun, produksi pangan pada ruang publik, serta produksi sayuran dalam ruang vertikal. Selain itu, keberadaan pertanian dalam masyarakat perkotaan dapat dijadikan sarana untuk mengoptimalkan pemanfaatan lahan dan sumberdaya alam yang ada di kota dengan menggunakan teknologi tepat guna. Selain itu, masyarakat kota yang umumnya sibuk karena bekerja, pertanian perkotaan dapat menjadi media untuk memanfaatkan waktu luang. Mengoptimalkan penggunaan lahan serta memanfaatkan waktu luang untuk beraktivitas dalam pertanian perkotaan akan mendekatkan mereka terhadap akses pangan serta menjaga keberlanjutan lingkungan dengan adanya ruang terbuka hijau.

\section{Jenis dan Presentasi Produk}

Video perancangan merupakan media informasi berbentuk animasi 2 dimensi dengan pembahasan mengenai introduksi urban gardening, pengenalan berbagai jenis tanaman dan konten aktivitas untuk berkebun di lahan sempit sesuai lokasi target penetapan perancangan. Dengan pertimbangan target audiens pada orientasi keluarga, maka gaya ilustrasi yang digunakan adalah gaya semi 
realis serta penggarapan karakter fiktif dari satu keluarga sederhana di perkotaan. Penggunaan ilustrasi semi realis didasari pada teori yang dikemukakan oleh Scott McCloud dalam buku yang berjudul Understanding Comics (1994) yang menyatakan bahwa usia muda hingga lanjut memiliki ketertarikan dengan ilustrasi bergaya semi realis menuju icon. Kemudian untuk berjalannya cerita didasari pada relevansi pada kehidupan nyata yang terjadi di masyarakat kota besar. Hal tersebut diinterpretasikan agar para orang tua terutama seorang ibu juga tidak lupa akan pentingnya sebuah pola asuh anak yang baik. Hal ini juga menimbulkan sebuah pesan moral yang baik mengenai kedekatan emosional antara orang tua dan anaknya.

Perancangan "Cara Urban Gardening yang Tepat Untuk Wilayah Kota DKI Jakarta" ini harus menentukan nama judul video tersebut agar lebih sesuai dengan target audiens, oleh karena itu judul video infografis yang akan dipublikasi dirancang berdasarkan positioning produk, yaitu berjudul "Kebunku Penuh dengan Cinta". Kemudian untuk spesifikasi video animasi infografis masuk dalam kategori vido panduan, berdurasi 2 menit, dengan resolusi 1280 pixel x 720 pixel. Warna dalam video dalam format RGB, gambar memiliki $30 \mathrm{fps}$, format H.264, audio stereo, Codec AAC dan Extensimp4. Untuk teknik video animasi yang digunakan adalah animasi dua (2) dimensi dengan pergerakan motiongraphic.

\section{Analisis Segmentasi}

Secara geografis segmentasi video ini ditujukan pada masyarakat kota-kota besar di Indonesia, yakni Jabodetabek. Secara demografis, video ini memiliki target utama yang ditujukan kepada kalangan anak-anak berusia 8-12 tahun dan ibu pekerja yang memiliki peran ganda berusia 30 tahun keatas. Dalam usia ini 812 tahun, anak tidak lagi bersifat egosentrisme yang berarti anak tidak lagi memandang bahwa dirinya merupakan pusat perhatian lingkungan. Akan tetapi anak lebih memperhatikan lingkungannya dengan objektif. Mereka mulai 
penasaran terhadap kenyataan dan mendorong dirinya untuk menyelidiki lingkungannya. Anak harus berikan kesempatan untuk banyak bergerak, berbuat dan bertindak.

\section{Penerapan Kreatif}

\section{Alur Cerita}

Cerita dalam perancangan ini merupakan relevansi antara aktivitas anak sekolah dasar jaman sekarang dengan orang tua yang menjadi pekerja kantor di dunia nyata. Dikisahkan 1 keluarga yang pindah dari desa ke perkotaan, dan mereka tinggal di sebuah perumahan kota besar. Orang tua yang bekerja sebagai pegawai kantoran sangat sulit untuk meluangkan waktu yang cukup lama dengan anak-anaknya, hal tersebut membuat anak-anak menjadi ketergantungan gadget. Anak-anak itu merupakan sosok kakak beradik bernama Jojo dan Jennie. Keduanya memiliki kepribadian yang unik dan cenderung berbeda satu sama lain. Orang tua yang selalu sibuk dengan urusan pekerjaan, membuat anak-anak yang tinggal di daerah perumahan tersebut sangat bosan dan kehilangan perhatian dari orang tuanya.

Jojo yang merupakan sosok kakak laki-laki yang sangat mandiri dan bersikap dewasa, menjadi kakak yang menjaga adiknya dengan baik. Jennie merupakan seorang adik perempuan yang periang dan juga sangat tergantung pada gadget, karena ia tidak memiliki kesempatan untuk belajar hal baru di lingkungan rumahnya. Akhirnya sang ibu memutuskan untuk mengajak mereka melakukan urban gardening guna mengurangi ketergantungan gadget dan dapat meningkatkan kedekatan secara emosional dengan anak-anaknya. Hal tersebut dijadikan tantangan oleh sang ibu, bahwa bila mereka berhasil memanen tanaman hasil urban gardening itu, sang ibu akan memberikan hadiah spesial kepada mereka, yakni sebuah gadget yang mereka impikan. Pada akhirnya kedua kakak 
beradik itu menyadari, bahwa urban gardening sangat menarik dan begitu seru untuk dilakukan dibandingkan bermain gadget.

\section{Skenario}

Berikut ini adalah perancangan naskah cerita atau skenario untuk cerita dalam video infografis urban gardening.

Table 1 Skenario percakapan

\begin{tabular}{|c|c|c|}
\hline Scene & Tokoh & Percakapan \\
\hline \multirow{5}{*}{$\begin{array}{l}\text { Scene } 1 . \\
\text { Perkenalan } \\
\text { tokoh cerita }\end{array}$} & Jojo & Halo teman-teman, perkenalkan nama saya Jojo \\
\hline & Jennie & Dan saya Jennie \\
\hline & Jojo & Dan ini adalah Papa Mama kami. \\
\hline & Papa dan Mama & Halooo \\
\hline & Jojo & $\begin{array}{l}\text { Nah.. Kali ini Jojo mau ajak kalian belajar yang asik bersama } \\
\text { Papa dan Mama nih... Penasaran gak? Yuks ikutin kegiatan } \\
\text { aku dan Jennie yah. }\end{array}$ \\
\hline \multirow[t]{8}{*}{$\begin{array}{l}\text { Scene } 2 . \\
\text { Awal Cerita }\end{array}$} & Jennie & $\begin{array}{l}\text { Kak Jo, lihat deh games ini gampang banget deh, kakak } \\
\text { mau coba kalahin nilai aku? }\end{array}$ \\
\hline & Jojo & $\begin{array}{l}\text { Mana coba Kakak liat? Hmm. Nggak ah ini kan games anak } \\
\text { kecil... mending Kakak nonton kartun bebek ini lebih seru. }\end{array}$ \\
\hline & Jenniw & $\begin{array}{l}\text { Mana? Mana? aku juga mau lihat donkk.. Kakak jangan } \\
\text { pelit.. }\end{array}$ \\
\hline & Mama & Eh.. eh.. ini ada apa yah? Kenapa pada ribut begini sih? \\
\hline & Jennie & Ini loh ma, si Kak Jo pelit, gak mau pinjemin hpnya ke aku.. \\
\hline & Jojo & yeee.. kamu kan punya hp sendiri! \\
\hline & Mama & $\begin{array}{l}\text { Udah.. udah.. jangan berantem, daripada kalian berdua } \\
\text { ribut karena main hp, mending ikut mama yukss... ini lebih } \\
\text { seru dan nggak bakal merusak mata kalian seperti hp kalian } \\
\text { ituh. }\end{array}$ \\
\hline & Jojo dan Jennie & $\begin{array}{l}\text { saling berpandangan lalu ikut Mama pergi ke halaman } \\
\text { belakang rumah. }\end{array}$ \\
\hline \multirow{5}{*}{$\begin{array}{l}\text { Scene } 3 . \\
\text { Introduksi } \\
\text { Urban } \\
\text { Gardening }\end{array}$} & Jojo & Ma kita mau ngapain? \\
\hline & Mama & Mama mau ajak kalian untuk melakukan urban gardening? \\
\hline & Jennie & Mama, Apa sih urban gardening itu? \\
\hline & Mama & $\begin{array}{l}\text { Urban gardening merupakan kegiatan menanam dan } \\
\text { menumbuhkan tanaman di area padat penduduk dengan } \\
\text { lahan kecil yang biasanya ditujukan untuk konsumsi } \\
\text { pribadi. Mirip dengan permainan tanam-menanam yang } \\
\text { kalian suka mainkan di hp kalian, hanya saja ini kita } \\
\text { dilakukan secara langsung.. seru kan.. }\end{array}$ \\
\hline & Jojo & $\begin{array}{l}\text { Owwww menarik yah Ma, terus.. terus... manfaatnya apa } \\
\text { donk Ma? Bukannya nanti kita jadi kotor Ma? }\end{array}$ \\
\hline
\end{tabular}




\begin{tabular}{|c|c|c|}
\hline \multirow[t]{7}{*}{$\begin{array}{l}\text { Scene } 4 . \\
\text { Manfaat }\end{array}$} & Mama & $\begin{array}{l}\text { Kotor pasti iyah, tapi kan bisa dibersihkan. Dengan } \\
\text { melakukan urban gardening kita bias dapat banyak } \\
\text { manfaat loh... }\end{array}$ \\
\hline & Jojo & Oww.. seperti... kita bisa makan hasil tanaman kita ma? \\
\hline & Jennie & Hah? Bener Ma? \\
\hline & Mama & $\begin{array}{l}\text { Bener kata kakak, dengan menanam sayur dan buah } \\
\text { sendiri, kita bisa dapat bahan makanan yang segar dan } \\
\text { sehat karena tanpa bahan pengawet, dan bahkan kita } \\
\text { menjadi lebih hemat. }\end{array}$ \\
\hline & Jojo & lyah, terus ada lagi Ma manfaatnya? \\
\hline & Mama & $\begin{array}{l}\text { Manfaat lainnya adalah kita turut berkontribusi } \\
\text { menghemat energi yang biasanya digunakan } \\
\text { mentransportasikan produk hasil pertanian dari kebun ke } \\
\text { tangan konsumen seperti kita dan paling penting adalah } \\
\text { kita juga berkontribusi membersihkan polusi udara di kota } \\
\text { kita ini. }\end{array}$ \\
\hline & Jojo & $\begin{array}{l}\text { Wah, sangat menarik yah Ma, terus Ma urban gardening } \\
\text { itu ada apa saja? }\end{array}$ \\
\hline \multirow{6}{*}{$\begin{array}{l}\text { Scene } 5 . \\
\text { Jenis jenis } \\
\text { urban } \\
\text { gardening }\end{array}$} & Mama & $\begin{array}{l}\text { Urban gardening bisa menanam sayur-sayuran, buah- } \\
\text { buahan hingga tanaman hias, sehingga dia banyak } \\
\text { jenisnya, contoh: Hidroponik, minimalis, vertikultur }\end{array}$ \\
\hline & & $\begin{array}{l}\text { Hidroponik adalah menanam menggunakan media air } \\
\text { tanpa tanah, agar tanamannya tubuh sehat kita harus terus } \\
\text { memperhatikan kadar air dan nutrisi untuk tanamannya. }\end{array}$ \\
\hline & & $\begin{array}{l}\text { Minimalis gardening adalah memanfaat tempat2 kecil } \\
\text { untuk menanam, cara ini masih membutuhkan tanah } \\
\text { sebagai media ataupun air, hanya saja untuk model ini kita }\end{array}$ \\
\hline & & $\begin{array}{l}\text { gga boleh memilih tanaman yang besar. } \\
\text { Vertikultur adalah cara menanam secara tegak lurus ke } \\
\text { atas, jadi kalau rumah kita tidak lebar, kita bisa mencoba } \\
\text { menanam dengan menyusun }\end{array}$ \\
\hline & Jojo & Susah gak sih Ma, alatnya apa ajah? \\
\hline & Mama & $\begin{array}{l}\text { Tidak susah kok Jo, yang penting kalian harus bersemangat } \\
\text { dulu nih.. }\end{array}$ \\
\hline \multirow{10}{*}{$\begin{array}{l}\text { Scene } 6 . \\
\text { Aturan } \\
\text { berkebun }\end{array}$} & Mama & Nah jadi, Kak Jo dan Jennie tertarik gga? \\
\hline & Jojo & Lanjut donk Ma \\
\hline & Jennie & lyah ma lanjut! \\
\hline & Mama & $\begin{array}{l}\text { Oke.. Sekarang mama akan ambil beberapa peralatan yang } \\
\text { kita perlukan }\end{array}$ \\
\hline & Jennie & asik.. \\
\hline & Jojo & yeahh.. \\
\hline & Mama & $\begin{array}{l}\text { Pertama kita butuh, beberapa wadah bekas, seperti } \\
\text { hmmm.. }\end{array}$ \\
\hline & Jennie & Kaleng bekas bisa ma? \\
\hline & Jojo & Botol Ma? \\
\hline & Mama & $\begin{array}{l}\text { Yah itu bisa semua, kalo kamu punya kotak makan yang } \\
\text { sudah rusak juga bisa kita gunakan. }\end{array}$ \\
\hline
\end{tabular}




\begin{tabular}{|c|c|c|}
\hline & Jojo & $\begin{array}{l}\text { Wahh... gak cuman menanam, ternyata kita juga bisa } \\
\text { melakukan daur ulang yah Ma. Terus sekarang apa lagi } \\
\text { Ma? }\end{array}$ \\
\hline \multirow[t]{13}{*}{$\begin{array}{l}\text { Scene } 7 . \\
\text { Cara } \\
\text { hidroponik, } \\
\text { minimalis, } \\
\text { vertikultur }\end{array}$} & Mama & $\begin{array}{l}\text { Yuks kita coba, yang hidroponik dulu yahh... coba mama } \\
\text { punya tanaman sayur apa yah.. (sambil mencari di } \\
\text { penyimpanan benih) } \\
\text { Nah ini daun bawang.. kita akan coba menanamnya } \\
\text { dengan wadah gelas ini yah.. } \\
\text { Pertama, kita ambil wadah ini da nisi air secukupnya, } \\
\text { jangan terlalu penuh yah.. airnya suhu ruangan aja.. } \\
\text { kemudian kita potong daun bawang ini sisakan kira2 satu } \\
\text { jengkal tangan kita, dan masukan daun bawang ini kedalam } \\
\text { wadahnya... kita tunggu bbrp hari yah untuk melihat } \\
\text { pertumbuhannya, nanti Jennie ukur tinggi tanaman kita } \\
\text { yah. }\end{array}$ \\
\hline & Jojo & Mama kalo yang pakai tanah gmana? \\
\hline & Mama & $\begin{array}{l}\text { Nah ini mama udah siapakan tanah yang sudah beli di toko } \\
\text { gardening, tanah ini udah di campur pupuk. }\end{array}$ \\
\hline & Jennie & Ma, Kita gak bisa pakai tanah yang ada di depan rumah aja? \\
\hline & Mama & $\begin{array}{l}\text { Yah boleh sih selama tanahnya subur, tapi kan tanah di } \\
\text { depan milik taman umum masa kita rusak Jennie. }\end{array}$ \\
\hline & Jojo & $\begin{array}{l}\text { lyah bener Jen! Kalo tanahnya aku ambil dari rumah kakek } \\
\text { di kampung boleh Ma? }\end{array}$ \\
\hline & Mama & $\begin{array}{l}\text { Tentu saja boleh, lain kali kita bawa pulang tanah yang dari } \\
\text { rumah kakek. Sekarang Jojo coba ambil biji-bijian yang } \\
\text { mama keringkan deket jendela. }\end{array}$ \\
\hline & Jojo & Ini ma? \\
\hline & Mama & $\begin{array}{l}\text { lyah ini biji cabe yang mama kering kan selama beberapa } \\
\text { hari, kita bisa juga beli bibitnya di took gardening, skrg kita } \\
\text { masukan kedalam tanah. Siram dikit2 yah jangan terlalu } \\
\text { banyak setiap hari... }\end{array}$ \\
\hline & Jojo & Kapan tumbuhnya Ma? \\
\hline & Mama & $\begin{array}{l}\text { Nah ini tugas Jojo mencatat yah.. perubahannya setiap } \\
\text { hari.. jadi kita bisa tau kapan kita akan memetik cabe kita } \\
\text { sendiri.. }\end{array}$ \\
\hline & Jennie & $\begin{array}{l}\text { Mama.. Jennie gak suka pedas, Jennie mau tanam wortel } \\
\text { bisa? }\end{array}$ \\
\hline & Mama & $\begin{array}{l}\text { Bisa donk, semuanya bisa dengan kedua cara tadi, nanti } \\
\text { kalo sudah banyak tanamannya kita2 tinggal kita susun ke } \\
\text { atas seperti ini agar tidak makan tempat. Jadi dehh } \\
\text { vertikultur gardening. }\end{array}$ \\
\hline \multirow{4}{*}{$\begin{array}{l}\text { Scene } 8 . \\
\text { Penutup }\end{array}$} & Jojo dan Jennie & yeahh asikkk.. \\
\hline & Jennie & Ini lebih seru daripada bermain hp yah kak Jo \\
\hline & Jojo & Benar! \\
\hline & Mama & $\begin{array}{l}\text { Nah serukan daripada main hp! Jadi lain kali kita coba } \\
\text { tanaman lain dan cara lain yah... }\end{array}$ \\
\hline
\end{tabular}




\begin{tabular}{c}
\hline Jojo dan Jennie Ayay Kaptenn!! \\
\hline Sumber: Nadya \& Erlyana, 2020
\end{tabular}

\section{Moodboard}

Look, mood, tone dan manner yang ditentukan dari video infografis ini dirancang dengan memiliki kesan segar, hijau dan menyejukkan sehingga keseluruhan itu divisualisasikan dengan pewarnaan lembut atau pastel serta terlihat edukatif. Moodboard yang dipilih merupakan kumpulan referensi visual yang bertema edukasi atau panduan anak dan gambar ilustrasi tanaman yang sesuai konsep mood yang ingin dibangun tersebut. Untuk membuat anak-anak lebih memahami visual tentang metode urban gardening, diputuskan untuk mengilustrasikan visual tanaman dan peralatan secara detail dan sesuai aslinya. Berikut ini adalah perancangan moodboard untuk cerita dalam video infografis urban gardening.

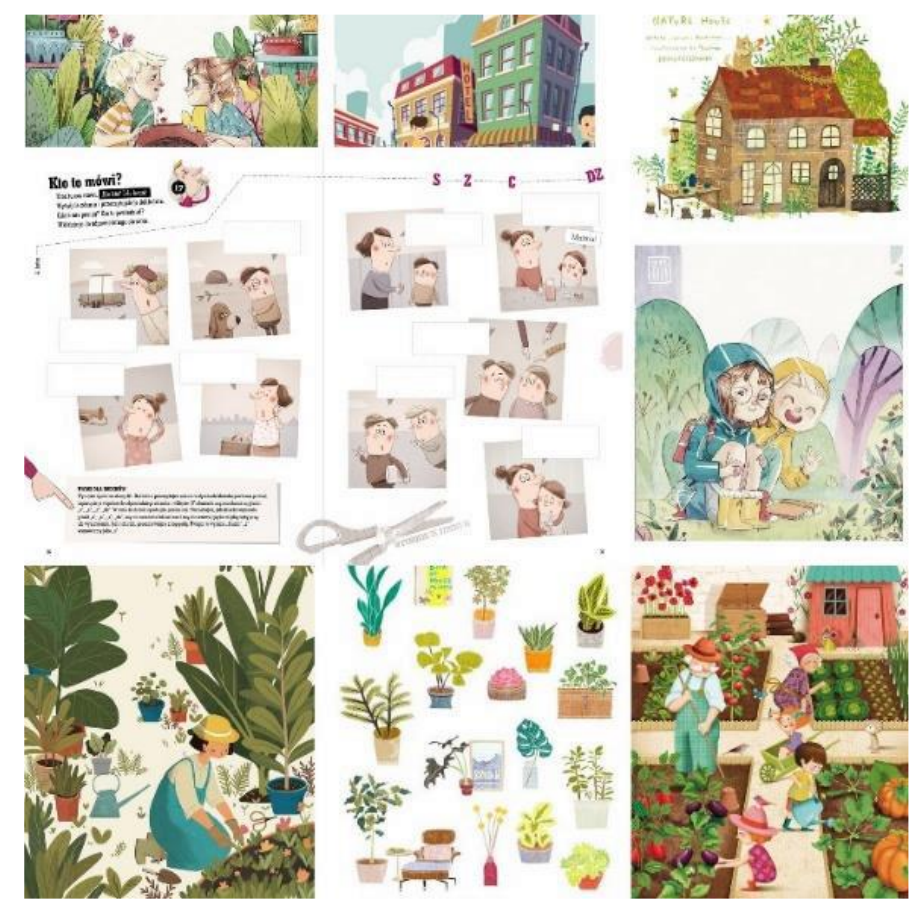

Gambar 1 Moodboard Perancangan

Sumber: Nadya \& Erlyana, 2020 


\section{Ilustrasi Karakter}

Jojo adalah karakter kakak laki-laki dalam cerita dengan pakaian garis horizontal dan tampil casual. Jojo adalah nama yang dipilih berdasarkan popularitas untuk anak laki-laki. Jojo dalam bahasa Indonesia, artinya memiliki sifat pengasih dan penyayang. Motif garis horizontal yang di kenakan Jojo, memiliki sebuah arti ketenangan. Warna kuning yang digunakan sebagai motif melambangkan bijaksana serta cerdas dari sisi akademis, lalu warna biru berkaitan dengan kepribadian yang melankolis serta menciptakan ketenangan. Dalam cerita, Jojo adalah seorang kakak laki-laki yang cerdas, tenang dan sangat menyayangi adiknya yang bernama Jennie.
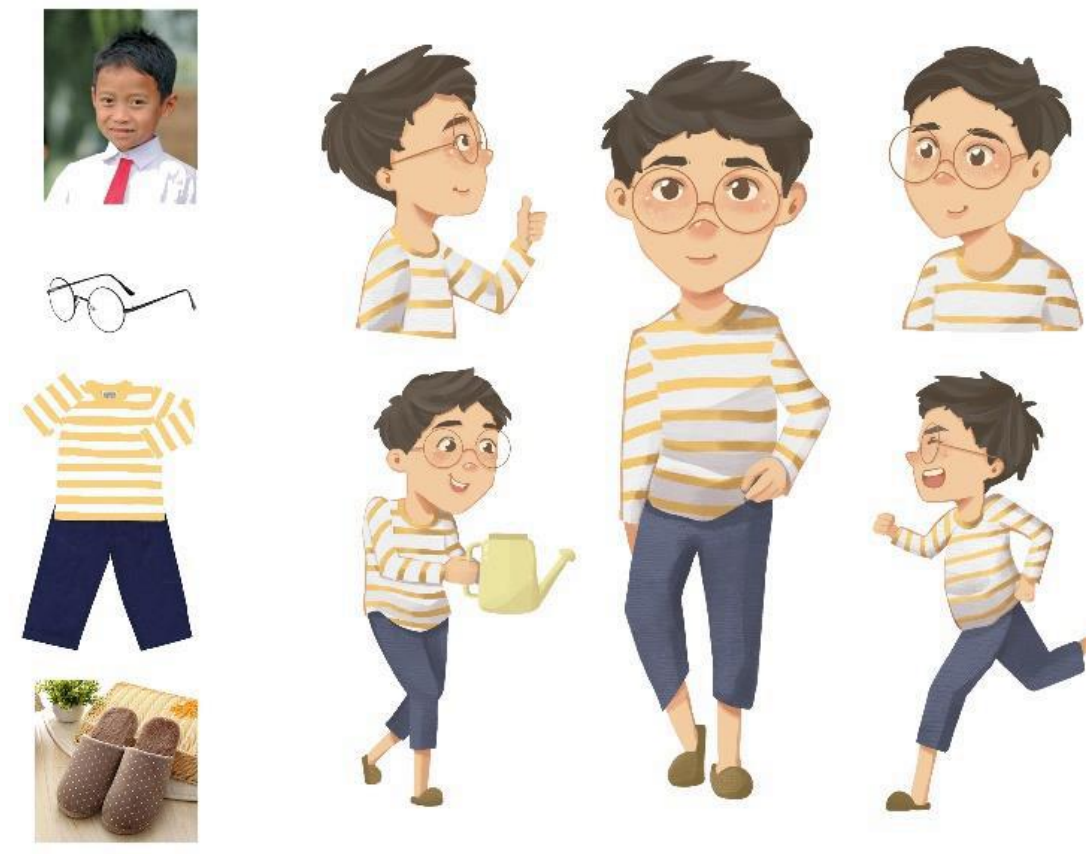

Gambar 2 Karakter Jojo

Sumber: Nadya \& Erlyana, 2020

Jennie adalah karakter adik perempuan dalam cerita dengan pakaian dress casual bermotif bulat (polka dot). Jennie dalam bahasa karakteristik, artinya ceria, penuh keyakinan, penuh semangat, menyukai petualangan dan hiburan. Motif bulat polka dot yang dikenakan Jennie, memiliki sebuah arti kebahagiaan dan 
optimisme. Warna pink dalam pakaian Jennie menandakan adanya kepedulian dalam dirinya. Dalam cerita, Jennie adalah seorang adik perempuan dari Jojo, Jennie sangat lucu, ceria dan semangat, terkadang dia sangat tidak terduga dan menggemaskan.
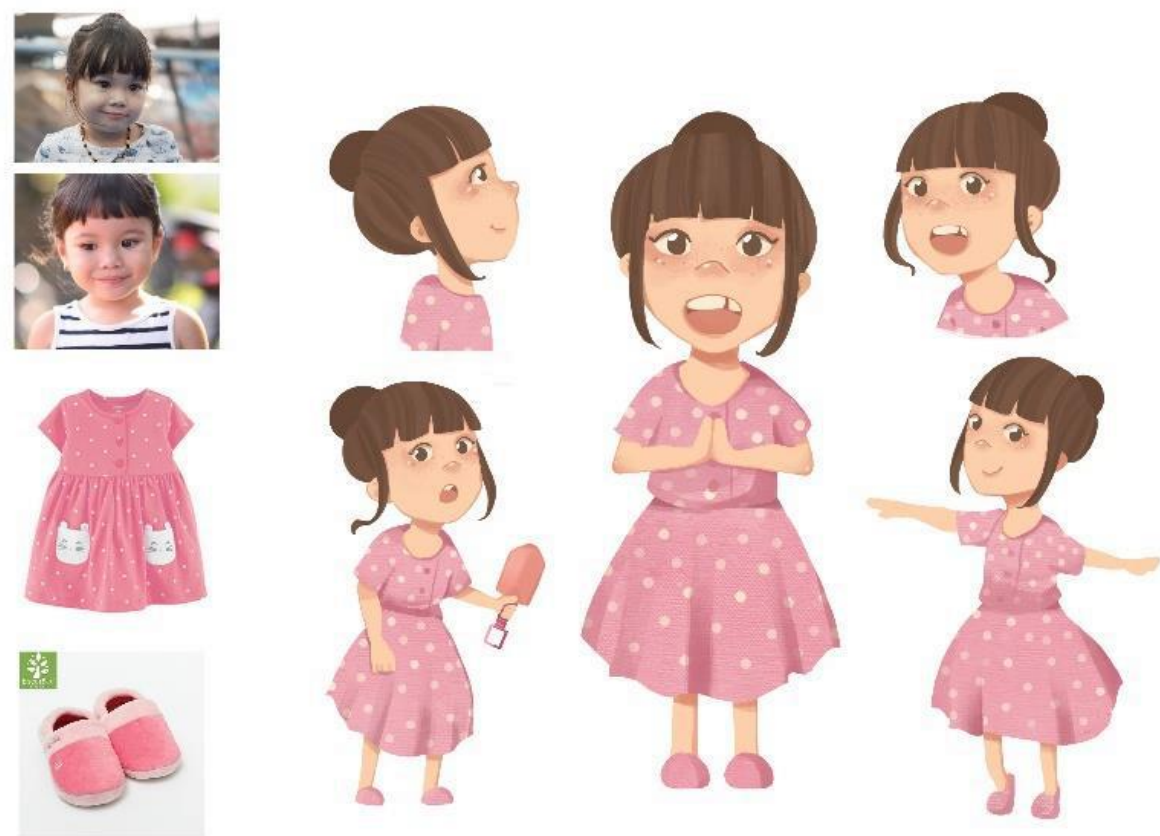

Gambar 3 Karakter Jennie

Sumber: Nadya \& Erlyana, 2020

Tokoh-tokoh pendukung dalam buku panduan urban gardening terdiri dari 2 karakter, yakni Juvia dan James. Mereka adalah Ibu dan Ayah dari tokoh utama. Juvia adalah seorang yang ambisius dan membaja bila diartikan dalam bahasa karakteristik. Dalam penokohan pada buku ini, Juvia adalah seorang ibu pekerja yang memiliki peran ganda dan perlu membagi waktu antara pekerjaan serta keluarga. James dalam Bahasa karakteristik artinya menarik dan penuh perhatian. Dalam penokohan pada buku ini, James adalah seorang ayah yang penyayang dan baik hati, ia seorang yang mengayomi anak-anaknya. 


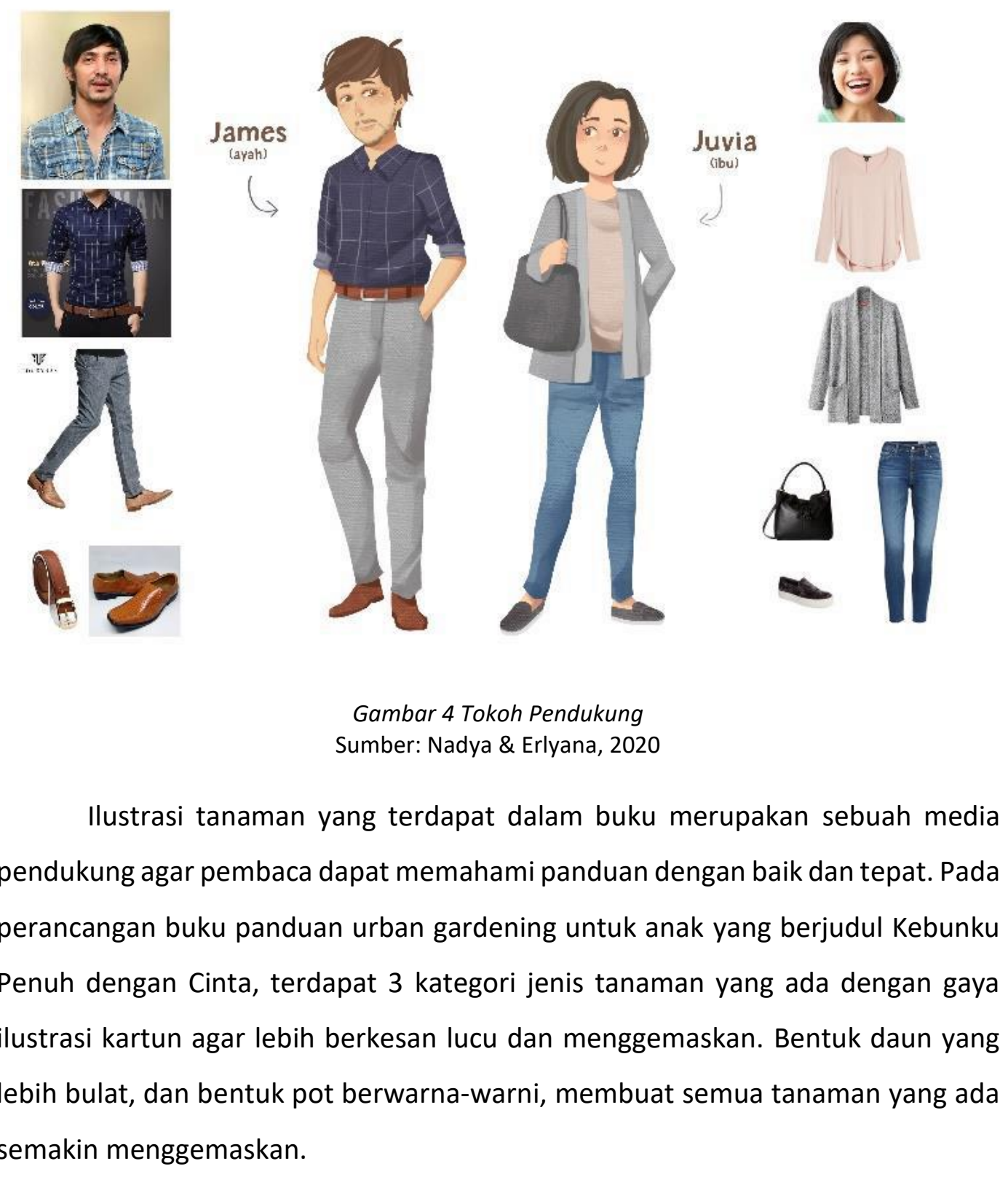


Table 2 Ilustrasi Tanaman dan Pendukung

\begin{tabular}{llll}
\hline No. & Nama & Referensi & Desain \\
\hline 1 & Tanaman Buah Tomat & \\
\hline 2 & $\begin{array}{l}\text { Tanaman Hias Bunga } \\
\text { Matahari }\end{array}$ & & \\
\hline 3 & Tanaman Sayur &
\end{tabular}

Sumber: Nadya \& Erlyana, 2020

Judul video infografis yang akan dipublikasi dirancang berdasarkan positioning produk, yaitu berjudul "Kebunku Penuh dengan Cinta". Oleh karena itu maka diperlukan perancangan judul dari sketsa hingga digitalisasi. Berikut ini adalah proses perancangan judul video dari sketsa hingga selesai. Judul ini diberi nama "Kebunku Penuh dengan Cinta" agar pembaca langsung mengetahui tema yang berada dalam video. Menggunakan jenis font "DK Sugary Pancake" untuk penulisan "KEBUNKU" ditambah dengan aksen dekorasi papan sebagai visual untuk menggambarkan ini merupakan sebuah material pembuat urban gardening. Lalu digunakan font "DK Cool Crayon" untuk penulisan "penuh dengan" agar terlihat fleksible dan seperti tulisan anak-anak. Selanjutnya font "Canterbury" pada tulisan "CINTA" menunjukan bahwa kesan sebuah tanaman gantung dengan aksen dekorasi tali yang menggantung ke papan. Ketiga hal tersebut saling terkait untuk memvisualisasikan sebuah ciri khas metode urban gardening. Selain judul 
utama, terdapat sub judul yang berfungsi untuk menjelaskan isi dari video. Video Infografis ini memiliki sebuah sub judul "Seri Pengenalan Urban Gardening untuk Anak" yang berarti memang video ini dikhususkan untuk panduan awal dalam melakukan metode urban gardening untuk anak.

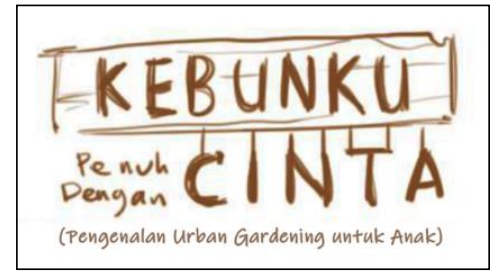

Gambar 5 Sketsa Judul Sumber: Nadya \& Erlyana, 2020

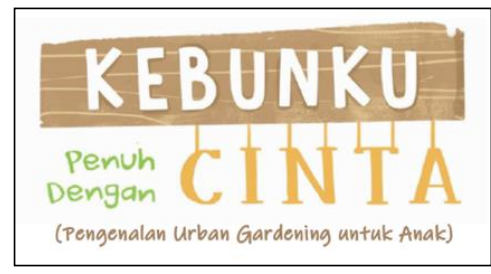

Gambar 6 Digitalisasi Judul Video Sumber: Nadya \& Erlyana, 2020

\section{Tipografi}

Jenis tipografi yang dipilih adalah jenis tipografi yang tidak terlalu kaku dan memiliki tingkat keterbacaan yang baik yang sesuai dengan target primer pada buku ini yaitu anak-anak berusia 8-12 tahun. Maka dari itu, dipilih jenis tipografi sans serif yang memiliki kesan hand writing lebih dominan dari pada serif yang hanya ada pada judul cover. Untuk judul buku "Kebunku Penuh dengan Cinta" menggunakan font 'DK Surgary Pancake' yang dimodifikasi latar belakangnya untuk terlihat seperti ditempel pada papan. Kesan bold juga memberikan dampak yang mudah dilihat oleh audiens. Lalu digunakan font "DK Cool Crayon" untuk penulisan "penuh dengan" agar terlihat fleksible dan seperti tulisan anak-anak. Selanjutnya font "Canterbury" pada tulisan "CINTA" menunjukkan bahwa kesan sebuah tanaman gantung dengan aksen dekorasi tali yang menggantung.

\section{Warna}

Pada perancangan video infografis ini, penulis banyak menggunakan unsur dominan warna hijau, krem dan coklat. Adapun warna pastel yang ditampilkan dalam buku ini yang menggambarkan suasana lingkungan alami yang ada di dalam 
rumah, suasana tersebut sangat segar bila dilihat dan dibaca oleh anak-anak Warna karakter yang ditampilkan dalam buku ini lebih ke arah warna cerah yang disukai anak-anak dan karakter tetap terlihat saat diaplikasikan dengan background perkebunan. Lalu terdapat warna pastel yang lebih cocok untuk warna tanamanya agar warna tanaman tetap terlihat lebih kuat dari pada warna latar belakang.

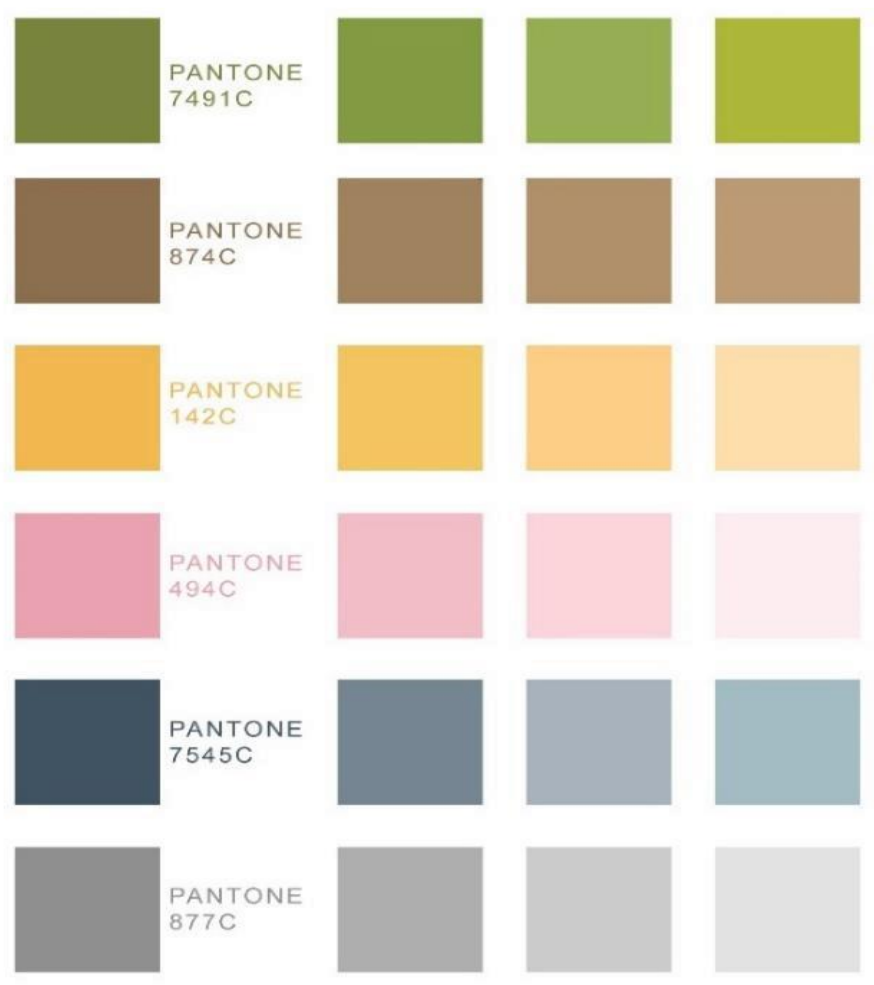

Gambar 7 Kunci Warna Perancangan Video

Sumber: Nadya \& Erlyana, 2020

\section{HASIL PERANCANGAN VIDEO ANIMASI}

Pada perancangan video infografis ini, terdapat animasi dengan total 8 adegan. Berikut ini adalah hasil penggambaran video infografisnya sebagai berikut. 


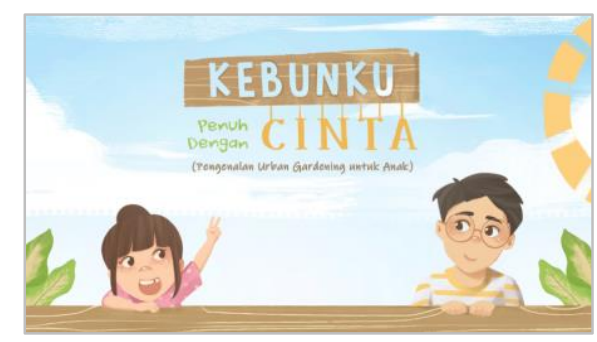

Gambar 8 Cuplikan Video Infografis Urban Gardening, Scene 01, Judul Video Sumber: Nadya \& Erlyana, 2020

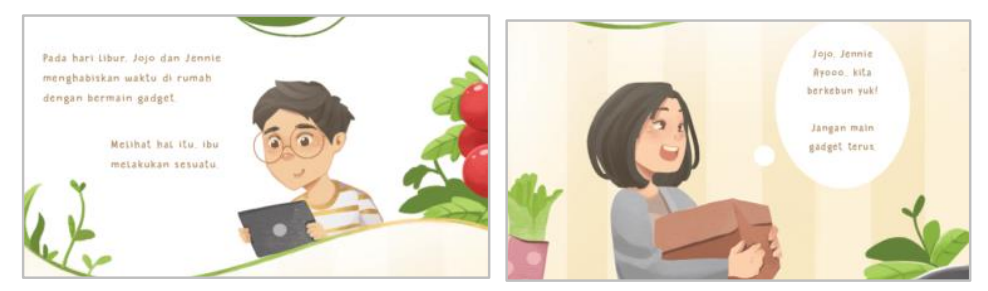

Gambar 9 Cuplikan Video Infografis Urban Gardening, Scene 02-03, Adegan Pembuka Sumber: Nadya \& Erlyana, 2020
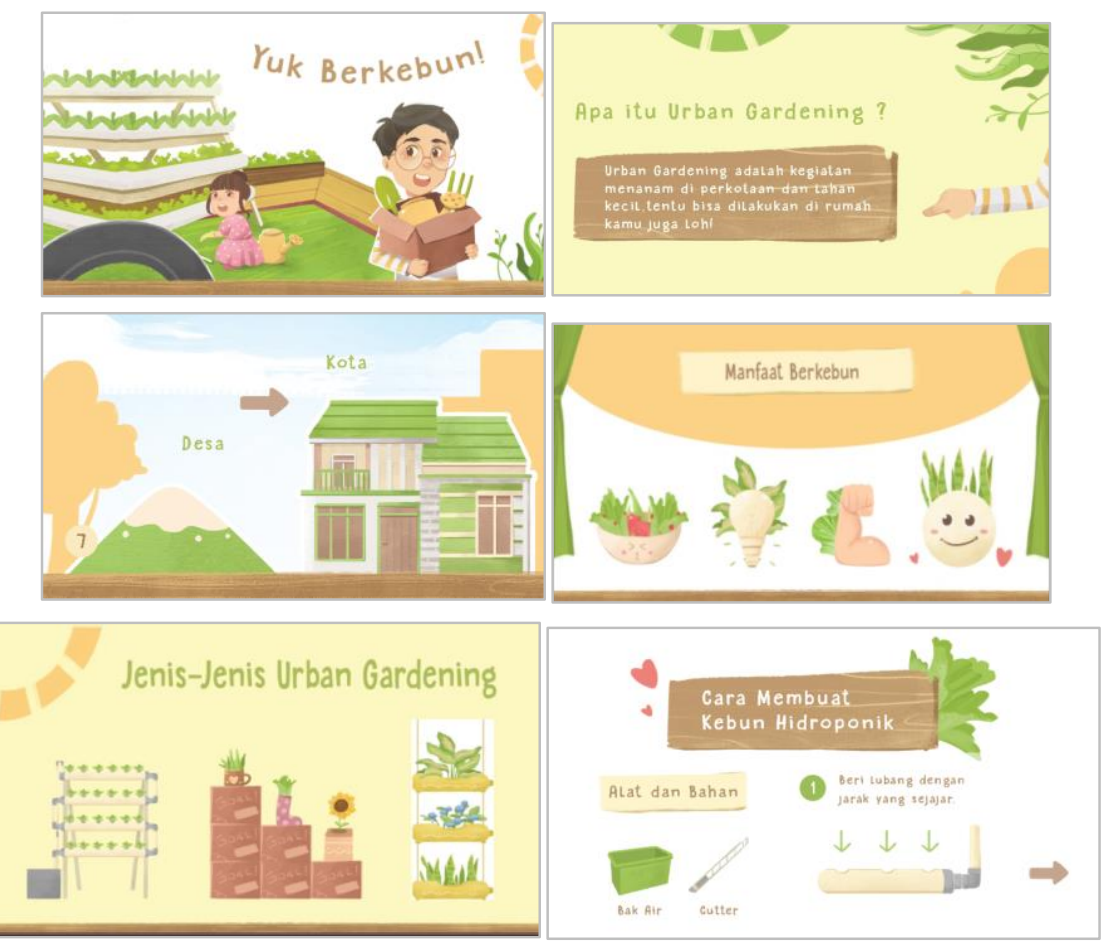

Gambar 10 Cuplikan Video Infografis Urban Gardening, Scene 04-09, Masuk Isi Cerita Sumber: Nadya \& Erlyana, 2020 


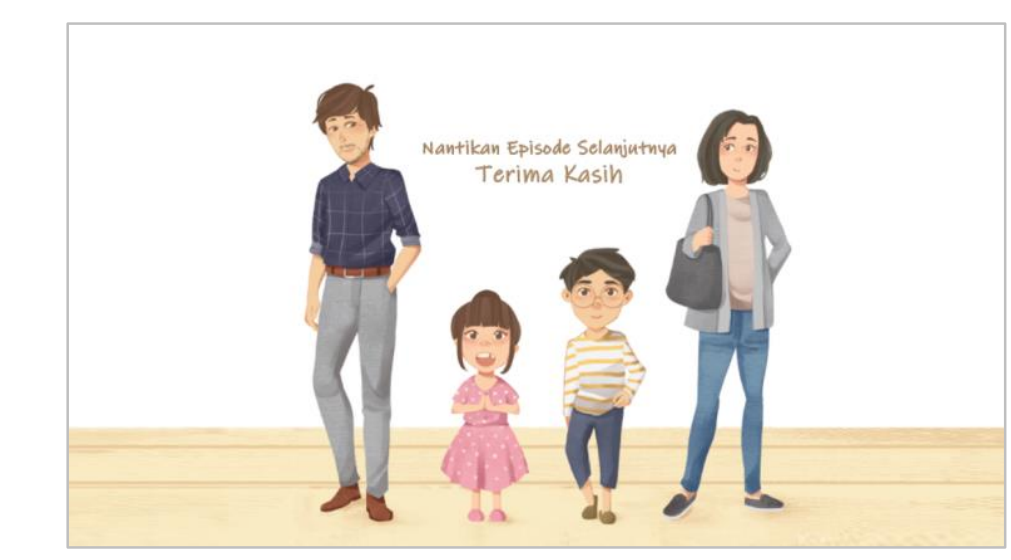

Gambar 11 Cuplikan Video Infografis Urban Gardening, Scene 10, Penutup Sumber: Nadya \& Erlyana, 2020

\section{KESIMPULAN}

Selama proses perancangan, banyak riset dan observasi yang dilakukan agar karya yang dihasilkan dapat diterima masyarakat terutama para anak-anak usia 812 tahun. Dalam menyusun konten materi yang membahas panduan untuk menanam terdapat kesulitan dalam membuat variabel yang bias dipakai untuk menentukan tanaman yang berada dalam video infografis. Setelah perancangan video, barulah masuk pada tahap produksi dan promosi. Berbagai macam media dipilih sebagai strategi distribusi video. Seluruh media yang digunakan menyesuaikan target primer video infografis urban gardening untuk anak. Dari perancangan penelitian ini, pembelajaran yang didapatkan ialah bahwa sebuah ilustrasi tidak hanya menjadi elemen untuk menarik perhatian masyarakat, melainkan dapat memandu konten edukasi yang disampaikan. Oleh karena itu diharapkan anak-anak tertarik untuk melakukan urban gardening dan dapat mengenal lebih jauh, karena memiliki dampak yang bermanfaat bagi anak-anak. Kekurangan dalam video ini adalah durasi konten yang diminati target cenderung terlalu singkat sehingga konten yang ingin diberikan tidak bias terlalu detail. Penelitian selanjutnya disarankan untuk dapat meneruskan topik ini dengan pengembangan seri selanjutnya. Untuk kajian data disarankan juga agar 
menggunakan teknik wawancara tatap muka sehingga bisa memperoleh jawaban yang lebih mendalam, masukan-masukan dari responden. Disarankan juga untuk meneliti tanaman-tanaman yang bisa ditanam dengan metode urban gardening melalui kajian pustaka lainnya.

\section{DAFTAR PUSTAKA}

Alfatra, F. F., Suminto, M. and Purwacandra, P. P. (2019) 'Penciptaan Film Animasi "Chase!" Dengan Teknik "Digital Drawing"', Journal of Animation and Games Studies, 5(1), pp. 033-056. doi: 10.24821/jags.v5i1.2799.

Dewi, R. S. and Rino, A. (2018) 'Animation as a Creative Industry: A Strategy to Build Creativity and Independence of Youth in Padang, West Sumatra', in Proceedings of MICoMS 2017 (Emerald Reach Proceedings Series), pp. 135141. doi: 10.1108/978-1-78756-793-1-00040.

Dur, B. I. U. (2014) 'Interactive Infographics on the Internet.', Online Journal of Art \& Design, 2(4), pp. 1-14. Available at: http://www.adjournal.net/articles/24/241.pdf.

Fauzi, A. R., Ichniarsyah, A. N. and Agustin, H. (2016) 'Pertanian Perkotaan: Urgensi, Peranan, dan Praktik Terbaik', Jurnal Agroteknologi, 10(01), pp. 49-62. Available at: https://jurnal.unej.ac.id/index.php/JAGT/article/view/4339.

Guntur (2016) Metode Penelitian Artistik. 2nd edn. Edited by A. N. Panindias. Jakarta: ISI Press.

Handani, S. W., Utami, S. and Kusmira, D. (2017) 'Visualisasi Pencemaran Air Menggunakan Media Animasi Infografis', Jurnal Telematika, 10(1), pp. 147-162. Available at: http://ejournal.amikompurwokerto.ac.id.

M, S. and Tyagi, S. K. (2018) 'Effectiveness of animation as a tool for communication in primary education', International Journal of Educational Management, 32(7), pp. 1202-1214. doi: 10.1108/IJEM-04-2016-0077.

Poggiali, J. (2018) 'Student responses to an animated character in information literacy instruction', Library Hi Tech, 36(1), pp. 29-42. doi: 10.1108/LHT12-2016-0149.

Priyono, L. A. et al. (2020) 'Penerapan Prinsip Animasi dalam Penciptaan Animasi 3D "Kepiting", Journal of Animation and Games Studies, 6(1), pp. 51-66. 
doi: 10.24821/jags.v6i1.3854.

Reno, T., Siahaan, A. U. and Alfian (2018) 'Implementasi Motion Grafis Video Animasi 2D Untuk', Journal of Digital Education, Communication, and Arts, 1(2), pp. 113-122.

Rimadi, L. (2019) 'Data AirVisual: Jakarta Kota Berpolusi Terburuk ke-3 di Dunia Pagi Ini', Liputan6.com. Available at: https://www.liputan6.com/news/read/4032507/data-airvisual-jakartakota-berpolusi-terburuk-ke-3-di-dunia-pagi-ini.

Riyanti, M. T. (2018) 'Pengembangan Model Pembelajaran Merencana Grafis Komersial Berbasis Proyek dengan Teory Dick \& Carrey', Seminar Nasional Pakar, 1(2), pp. 1-7.

Rutherford, J. I. (2019) 'A therapeutic approach to learning through creative storytelling', Advances in Dual Diagnosis, 12(1-2), pp. 85-98. doi: 10.1108/ADD-11-2018-0021.

Sari, I. P. (2019) 'Perancangan Video Edukasi Animasi 2 Dimensi Berbasis Motion Graphic Mengenai Bahaya Zat Adiktif untuk Remaja', Jurnal Pendidikan Multimedia, 1(1), pp. 43-52.

Stevina, D. and Purwaningsih, D. A. (2018) 'Character Designing with Visual Approach for Puppet Animation in A Hybrid Short Animation "Ihan"', International Journal of Asia Digital Art and Design Association, 22(1), pp. 32-37. doi: 10.20668/adada.22.1_32.

Subagio, J. (2019) 'Jakarta Masih Kekurangan Ruang Terbuka Hijau, Ini Penjelasan Ahli', Kompas.com, 27 June. Available at: https://sains.kompas.com/read/2019/06/27/200400723/jakarta-masihkekurangan-ruang-terbuka-hijau-ini-penjelasan-ahli.

Susilowati, I. and Nurini (2013) 'Konsep Pengembangan Ruang Terbuka Hijau (RTH) pada Permukiman Kepadatan Tinggi', Jurnal Pembangunan Wilayah \& Kota, 9(4), pp. 429-438. doi: 10.14710/pwk.v9i4.6680.

Yuvaraj, M. (2017) 'Infographics: tools for designing, visualizing data and storytelling in libraries', Library Hi Tech News, 34(5), pp. 6-9. doi: 10.1108/LHTN-01-2017-0004. 